spectrum with the Potsdam $30-\mathrm{cm}$. reflector. This plate reveals strong emissions of $\mathrm{He}$ II at $\lambda .5411$ and of the nebular lines of [O III] at $\lambda 5000$, the width being about $200 \mathrm{~A}$. The continuous spectrum resembles that of a $B$-type star. Neutral helium at $\lambda 4471,4388,4144,4026$ appears in absorption. The Balmer lines are present as faint emissions, perhaps with violet absorption companions.

The photographic light curve of this super-nova, "145.1937 Persei", has recently been discussed by A. Beer and C. C. L. Gregory before the Royal Astronomical Society. This paper was based on a number of plates secured with the 24-in. Wilson reflector of the University of London Observatory at Mill Hill. The results show that the brightness of this nova was also fading rapidly. From $13 \cdot 3 \mathrm{~m}$. on September 20 it decreased to $13.8 \mathrm{~m}$. on September 26 , to $14.6 \mathrm{~m}$. on October $3-4$, and to $15 \cdot 4 \mathrm{~m}$. on October 9-10. Soon afterwards the star had become too faint for these observations. A high positive colour index is indicated, the visual brightness on October 12 being greater by $1.7 \mathrm{~m}$. than the photographic value. No reports from the large American observatories are yet available, and nothing is known up to now about the doubtlessly very interesting spectroscopic results obtained there.

\title{
Development of Co-axial Cables for Television
}

$\mathrm{O}^{\mathrm{N}}$ $\mathrm{NE}$ of the results of the modern developments in television technique has been the production on a commercial scale of cables capable of transmitting, with reasonable efficiency, alternating electric currents at frequencies up to one or two megacycles per second. These cables, which are of the concentric or co-axial type, are employed in the first place for conveying from the studio or outdoor scene to the television transmitter, the modulation frequency currents of the scene being televised. Such a cable is, for example, employed by the B.B.C. to connect the Alexandra Palace station to Broadcasting House and other important places in central London. But the scope of the application is now being extended to the use of the cables for the interconnexion of television transmitting stations separated by distances of the order of 100 miles. When the distance covered is of this order, the use of the cable is by no means limited to television, since the frequency band avail. able provides a large number of ordinary telephone channels along the cable, thereby considerably augmenting the normal land-line trunk-connexion facilities. By a suitable arrangement of the relative frequencies, these telephone channels can be operated simultaneously with the transmission of the television signals, and the value of the cable is thus considerably enhanced. At the present time, a high-frequency co-axial cable is being installed by the Post Office between London and Birmingham, and the results of its operation will be awaited with interest.

Although Great Britain has been the pioneer country in operating a public television broadcasting service, the development and installation of these cables have been proceeding elsewhere, notably in Germany and the United States. The Wireless World of December 30 contains a note on the work of the German Post Office on a scheme for the linking. up of Berlin with other important towns. The cables in contemplation or actually undergoing installation will provide interconnexion between the television stations; the Post Office will further provide television-telephone facilities and in addition, arrangements have been made for sending as many as two hundred telephone conversations along the new cables in the frequency band not required by the television currents. For the purpose of transmitting television pictures on a basis of 441-line definition and interlaced frames at 25 per second, it will be necessary to instal amplifiers or repeaters at intervals of 10-12 miles along the cable. These repeater stations will be entirely unattended and will be supplied with power-frequency alternating current passed along the cable. Three types of cable made by different firms are being employed, and it is anticipated that the installations will be completed during the current year.

An interesting demonstration of the possibilities of these co-axial cables was provided last November by the transmission of a sound-picture film between New York and Philadelphia, a distance of ninety miles. This matter was briefly referred to in NATURE of December 4 (p. 962), and further details of the experiment have now been supplied by the Bell Telephone Laboratories. The cable in this case consists of two co-axial conductor units, each of which is formed of a flexible copper tube and a single concentric wire insulated at intervals with ebonite disks. Along the route are situated unattended installations of special amplifying equipment which receive their power supply over the two inner conductors. Each of the co-axial conductors with its associated one-way amplifiers is capable of transmitting simultaneously the currents from 240 telephone transmitters. Thus, using the two units of the cable for transmission in opposite directions, the system provides for 240 simultaneous conversations. In the present arrangement, the transmitters are formed into twenty groups of twelve, each transmitter being limited to a frequency band of four kilocycles per second. For the transmission of vision or picture signals, practically the entire frequency band of the cable-about one million cycles per second-is utilized.

In the demonstration to which reference was made above, a cinematograph film moving uniformly past a gate where it was scanned by a rotating disk system at a rate corresponding to 240 lines and 24 frames per second was used to provide a picture. The light passing through the film entered an electron multiplier, and the resulting current contained component frequencies between zero and about 800 kc./sec. For transmission along the cable, the frequency of this signal current was raised by modula. tion about $100 \mathrm{kc} . / \mathrm{sec}$. in order to avoid the portion of the range where transmission would be unsatisfactory and amplification difficult. In passing along the cable, the lowest frequencies fall behind the highest by a time amounting to some twenty microseconds. Delay equalizers were therefore developed to secure equal transmission times for all frequencies 
to within a quarter micro-second. At the receiving ond a cathode ray tube was employed to produce a picture about eight inches square, and the demonstration provided satisfactory and clear reproduction of the scenes portrayed on the film at the sending end.

At the conclusion of the demonstration Dr. F. B. Jewett, president of the Bell Telephone Laboratories, stated that the experimental development was pro- ceeding with the view of extending the operating frequency range of the cables and associated apparatus to at least two megacycles per second. This would provide a system capable of accommodating the maximum number of telephone channels which it is economical to handle on such a cable, or the widest band of frequencies which the best television scanning and reproducing apparatus may require.

\section{Fuel Research in Great Britain}

$\mathrm{T}$ HE annual report of the Fuel Research Board is always an interesting document because it covers so wide a range of topics that the reader can gain a fair conspectus of the problems engaging the attention of fuel technologists at the moment. The Coal Survey of Great Britain is probably, taking the long view, its most important task, and steady progress is recorded. With time, the scope of its activities increases as increased refinement in fuel processes makes greater demands on the supplies of raw fuel. The demand for cleaned, closely sized fuel grows at the expense of that for large lumps, and this creates many problems. The problem of breaking coal, removing dust and fine coal, clarifying wash water grow in importance. In Yorkshire, efforts are being made to reduce the number of standard sizes, which are bewildering in their number and names. The dust-proofing of coal by spraying it with suitable oil or other liquid to prevent the raising of dust when disturbed is another problem receiving study.

The investigation of the production of oil from coal continues. The staff at Greenwich has studied the process of carbonization at low temperatures from the outset and evolved a design of vertical retort for the purpose. It is now reported that a setting of these retorts has been in operation at the South Yorkshire Chemical Works Ltd., near Rotherham, during the period under review and has given entire satisfaction.

A more comprehensive account of the Fuel Research Board's work on domestic fuels is found in Technical Paper No. 46, describing the results of Mr. J. S. Hales' observations on the use of coke in open fires ${ }^{2}$. Although it covers some ground previously traversed by others, only good can follow repeated assertion of experimentally ascertained facts so imperfectly known or understood. Although fire has been used by man through the ages, until recently no quantita. tive answers could be given to some of the simplest questions. This is exemplified in Mr. Hales' report, for he deemed it necessary to show by experiment that the rate of combustion of an open fire is not changed by opening or closing a canopy, if fitted.

Great ignorance prevails as to the relative merits of coals and cokes so that the view-encouraged by some coal merchants-is common that coke is a debased fuel fit only for the indigent. In this connexion, the general conclusion of this report is important, namely, that " combustible' coke may be superior to normal household coal from the point of view of freedom from smoke, easy ignition and rate of initial combustion, but that the control of the rate of radiation of heat can be more easily achieved with coal". It ought to be pointed out that a measure of control is possible, but the consumer needs educating in the technique of using carbonized fuels.

The basis of test used is the measurement of radiation in one direction emitted by a fixed volume of fuel in a single charge. This method gives useful information capable of interpretation by a discerning reader. Fuel, however, is bought by weight, and the undiscerning reader may get a wrong idea of the comparative cost of the unit of radiated heat, from the statement that the maximum radiation from a normal household coal may exceed by 30 per cent that from a coke. This apparently relates to equal volumes of fuel and the fact is obscured that the rate of consumption of the coal probably exceeds that of coke by 50 per cent.

The third report of the Oil from Coal Committee issued by the Scottish Development Council merits attention not merely for its contents, but also as an example of local initiative ${ }^{3}$. Areas hit by depression may have been richly endowed with natural resources. Those who have exploited these resources have often been content to take out great wealth without 'ploughing in' sufficient to develop subsidiary industries. Thus a decline in the main industry leaves the area economically stranded. The efforts of the Scottish Development Council set a good example of the local self-help by scientific study of the possibility of grafting new industry upon old stock. The report deals with experiments on the low temperature carbonization of Scottish coal, but the conclusions are not too hopeful as to the economic aspects.

The Duke of Montrose criticizes the manner in which the Committee has approached the problem of marketing, and there is force in his criticism. No one familiar with the matter will expect the use of raw coal to be easily displaced and the consumer must be educated to understand the conclusions of the Technical Paper No. 46 (v.s.), namely, that cokes have advantages as well as disadvantages. The technique of using them must be taught and the organization of sales and distribution will require effort, otherwise the best laid scheme may fail. Thus in one town municipal houses were fitted with grates suitable for burning coke, but no organization was provided for the regular distribution of suitable fuel in small quantities; the tenants consequently burn coal delivered at the door.

H. J. H.

${ }^{1}$ Department of Scientific and Industrial Research. Report of the Fuel Research Board for the year ended March 31, 1937 ; with Report of the Director of Fuel Research. Pp. ix $+213+5$ plates. (London H.M. Stationery Office, 1937.) 38. 6d. net.

¿ Department of Scientiflc and Industrial Research : Fuel Research Technical Paper No. 46: "The Use of Coke in Open Domestic Grates". By J. S. Hales. Pp. vi +50 . (London: H.M. Stationery Office, 1937.) 18. net.

'Scottish Development Council. Economic Series No. 14 : Scottish Industry-Third Report of the "Oil from Coal" Committee. (Revised.) Pp. 46. (Glasgow: Scottish Development Council, 1937.) 6d. net. 